\title{
Laboreal
}

Volume 12 №2 | 2016

Equipamentos de Proteção Individual II

\section{Queijo: o modelo do queijo suíço (um velho desconhecido)}

Queso: el modelo del queso suizo (un viejo desconocido)

Le modèle du fromage suisse (un vieux méconnu)

The Swiss cheese model (an unknown old)

\section{Diego Turjanski}

\section{(2) OpenEdition}

\section{Journals}

\section{Edição electrónica}

URL: http://journals.openedition.org/laboreal/2740

DOI: $10.4000 /$ laboreal. 2740

ISSN: 1646-5237

\section{Editora}

Universidade do Porto

\section{Refêrencia eletrónica}

Diego Turjanski, «Queijo: o modelo do queijo suíço (um velho desconhecido) », Laboreal [Online], Volume 12 N² $^{\circ}$ | 2016, posto online no dia 01 dezembro 2016, consultado o 15 setembro 2020. URL : http://journals.openedition.org/laboreal/2740

Este documento foi criado de forma automática no dia 15 setembro 2020.

\section{(c) (†) 8}

Laboreal está licenciado com uma Licença Creative Commons - Atribuição-NãoComercial 4.0 Internacional. 


\title{
Queijo: o modelo do queijo suíço (um velho desconhecido)
}

\author{
Queso: el modelo del queso suizo (un viejo desconocido) \\ Le modèle du fromage suisse (un vieux méconnu) \\ The Swiss cheese model (an unknown old)
}

\section{Diego Turjanski}

\section{NOTA DO EDITOR}

http://dx.doi.org/10.15667/laborealxii0216dtpt

\section{Introdução}

1 Há pouco tempo, ocorreu um congresso sobre segurança operacional no qual o responsável máximo de uma organização industrial multinacional de grande dimensão apresentou a sua "visão da segurança". À frente, podia observar-se um quadro de grandes dimensões onde estava projetado o modelo do queijo suiço. Mas nessa cena havia algo que era dissonante: por um lado, as ideias de James Reason projetadas no quadro e, por outro, um discurso que sistematicamente apelava, como argumento principal, à segurança baseada nos comportamentos dos trabalhadores e dos supervisores. A ideia central que essa pessoa tentava transmitir na sua apresentação era que, de acordo com as ideias de James Reason, era necessário supervisionar mais as pessoas, desenvolver políticas de gestão de segurança menos laxistas e aumentar, entre outros elementos, o controlo do comportamento dos trabalhadores e supervisores, a fim de otimizar a segurança das operações.

2 Foi essa a primeira vez que pudemos observar, com toda a clareza, um fenómeno muito interessante: apesar de o famoso modelo estar "instalado" há vários anos tanto no mundo da indústria (na aviação, indústria petrolífera, medicina, para referir apenas 
alguns setores), como no âmbito académico, a sua interpretação e a sua utilização "na prática" parecem mostrar algumas discrepâncias muito significativas.

Podemos facilmente constatar, noutros planos, estas divergências. Por um lado, basta fazer uma pesquisa rápida na Internet para verificar que há tantas representações gráficas do modelo do queijo suíço de Reason, como autores ou oradores que tenham tentado explicá-lo. Por outro lado, basta parar para ouvir e ler as interpretações que se fizeram em artigos, livros, ferramentas de gestão da segurança [1] ou palestras em eventos científicos, para compreender que as diferenças não obedecem simplesmente à "forma gráfica" do modelo, mas que implicam também verdadeiros "abismos" conceptuais. E foi o próprio autor que nas suas diversas publicações alterou substancialmente o seu ponto de vista ao longo dos anos, resultado de um evidente trabalho intelectual de "ida e volta" entre o mundo real dos "factos" e o mundo "ideal" da modelização.

Em resumo, parece ser uma constatação que em alguns âmbitos (sejam eles académicos ou da prática profissional) se considere este modelo como "óbvio", julgando-o "antiquado", "repetitivo" ou "sobejamente conhecido", mesmo quando existem evidências claras e empíricas de que o modelo do queijo suíço continua a ser um terreno confuso, tanto numa perspetiva conceptual, como numa perspetiva prática.

Nesse sentido, cremos que existem duas razões fundamentais que contribuem para explicar (pelo menos em parte) este fenómeno. Em seguida, apresentaremos em pormenor essas razões.

\section{A própria evolução das ideias de Reason}

6 É evidente (sem que tal que não dispense justificação) que a própria evolução das ideias de Reason favoreceram, de uma forma ou de outra, diferentes interpretações do modelo. Um dos primeiros antecedentes importantes do modelo do queijo suíço pode situar-se numa das suas obras mais conhecidas, "El error humano" [2], que data de 1990. As ideias mais "sistémicas" de Reason surgem nesta publicação de forma muito incipiente e prova disso é o próprio desenvolvimento dos conteúdos da obra, onde se dedica uma grande parte à compreensão dos mecanismos cognitivos individuais associados ao erro humano, sendo reservado apenas um capítulo à compreensão das "falhas latentes" imputadas aos sistemas. Nesta publicação, as intenções do modelo incidem "marcadamente" nos indivíduos, quer sejam os operadores que se situam nas primeiras linhas da situação de trabalho (com efeito, na modelização, a "janela" que se pode ler imediatamente atrás dos "Atos inseguros" é a de "Precursores psicológicos"), ou os que se situam "mais acima" na pirâmide hierárquica (a "janela" que se segue aos precursores psicológicos denomina-se "falhas latentes nos níveis de direção").

Esta questão revela-se importante na medida em que a partir dessa perspetiva "antiga" do modelo do queijo suíço surgiram (e cristalizaram-se) algumas interpretações "individuais" acerca da génese de acidentes. Na verdade, é muito comum que, sob uma certa pretensão de "novidade", este tipo de leitura das ideias de Reason apele a uma explicação "dissimuladamente antiga" da segurança. Assim, o "erro humano" do operador já não seria tratado como o fator-chave na explicação dos eventos, mas sim o "erro humano" do supervisor, ou do gerente, que pode explicar o sucedido com maior grau de "profundidade". Definitivamente, mais do mesmo. 
8 Contudo, as ideias de Reason continuaram em franca evolução. Já na sua seguinte publicação importante, La gestión de los grandes Riesgos [3] (que data de 1997), as suas ideias parecem ter sofrido uma reviravolta significativa e são apresentadas de forma consideravelmente diferente. Na modelização apresentada nesta obra é possível observar que as instâncias imediatamente anteriores aos atos perigosos são os "Fatores locais do contexto de trabalho" e os "Fatores Organizativos". Nesta fase dos desenvolvimentos de Reason, não há dúvidas acerca da evidente intenção do modelo do queijo suíço de capturar a origem organizativa dos grandes acidentes. 0 erro do operador de primeira linha já não aparece associado a um precursor psicológico, nem a outro erro dentro da cadeia hierárquica, mas sim ao próprio desenho do contexto próximo de trabalho e, a montante, aos problemas de "desenho organizativo".

9 Finalmente, e como se não bastasse, é o próprio Reason que numa obra posterior, $L a$ contribución humana, Actos peligrosos y acciones ejemplares, que data de 2008 [ ${ }^{4}$, efetua uma revisão das "fases de desenvolvimento" do modelo do queijo suíço, marcando claramente a evolução das suas próprias ideias.

10 Em síntese, a própria evolução do enfoque de James Reason (desde a primeira ótica mais individual, até as suas seguintes versões mais sistémicas) parece ter contribuído, em certa medida, para o surgimento de discrepâncias nas formas de interpretar as ideias conceptuais e operativas que emanam do modelo do queijo suíço.

\section{Modelos para pensar acerca dos fracassos em segurança}

11 Tal como sublinhado por Hollnagel (2009), é por demais evidente que não podemos pensar acerca do nosso contexto fora de certos paradigmas, isto é, fora de um conjunto de ideias acerca da forma como funciona a realidade. No entanto, o que é mais comum a certos paradigmas, sobretudo no mundo corporativo, é a sua propensão para se instalarem de forma implícita e mais ou menos invisível. No campo da segurança, este fenómeno foi descrito por Hollnagel com base na ideia dos modelos de análise de acidentes. Os paradigmas na análise de acidentes podem ser compreendidos, com efeito, como um conjunto de crenças, mais ou menos partilhadas, sobre os mecanismos de causalidade subjacentes aos acidentes e, de forma mais geral, aos fracassos em matéria de segurança.

12 Os primeiros quadros explicativos de acidentes foram os chamados modelos lineares ou sequenciais. Estes baseiam-se, fundamentalmente, na ideia de que os acidentes são o resultado de uma sequência de causa-efeito de eventos, cujo desencadeador inicial pode ser encontrado, quase invariavelmente, no comportamento dos operadores de primeira linha. Apesar de ser evidente que o modelo linear assenta em bases muito questionáveis, foi bastante difundido e aplicado em diversos setores industriais e utilizado na prática através de diversas metodologias que ainda continuam a ser amplamente difundidas.

13 Contudo, estas ideias evoluíram com os chamados modelos epidemiológicos ou sistémicos [5]. Contrariamente aos anteriores, estes modelos recorrem a explicações mais complexas e dinâmicas. Com efeito, defendem que o erro humano não é o fator que provoca os acidentes, mas que, pelo contrário, é a consequência (ou seja, o sintoma) de uma multiplicidade de falhas do sistema mais profundas, que devem ser 
monitorizadas de forma distanciada no tempo e no espaço face ao desencadeamento próximo do evento.

Apesar de o modelo do "Queijo Suíço" ter sido desenvolvido (sobretudo na sua última etapa de formulação) para ilustrar de uma forma clara e pedagógica as premissas do modelo sistémico ou epidemiológico, é extremamente frequente que seja utilizado para fundamentar determinadas leituras lineares dos problemas de segurança, de forma mais ou menos dissimulada. A predominância da defesa dos modelos "lineares" como quadros interpretativos da realidade explica (em boa medida) as leituras "lineares" do modelo do queijo suíço, inclusivamente em algumas versões que afirmam explicitamente adotar premissas sistémicas. Mesmo não se enquadrando no âmbito deste artigo, importa assinalar que a mesma discrepância prática e conceptual pode ser observada na permanente confusão do campo dos "Fatores humanos" com o das ciências do comportamento.

\section{Conclusão}

Apesar de o modelo do queijo suíço ter tido uma ampla difusão tanto no meio académico como no meio corporativo e na prática profissional, as suas interpretações e aplicações foram muito diversas e heterogéneas, favorecendo em muitas circunstâncias uma consolidação do enfoque "individual" na explicação da génese dos problemas de segurança.

Este fenómeno pode ser compreendido através de duas explicações fundamentais: em primeiro lugar, a própria evolução das ideias de Reason, que incidiram inicialmente nos aspetos cognitivos e individuais do desempenho humano, o que parece ter favorecido a perpetuação de determinadas leituras lineares do modelo. Em segundo lugar, a própria inércia do enfoque linear, que continua a funcionar como quadro interpretativo dos problemas de segurança, favoreceu também uma leitura "individual" das próprias premissas do modelo.

17 Retomar as premissas sistémicas do modelo do queijo suíço e levá-las à prática real da segurança é, portanto, um desafio evidente na busca da otimização da capacidade de pensar e atuar sobre os problemas de segurança.

\section{BIBLIOGRAFIA}

Hollnagel, E. (2009). Barreras y prevención de accidentes. Editorial Modus Laborandi. Madrid.

Reason, J. (2009). El error humano. Editorial Modus Laborandi, Madrid. (Obra originalmente publicada em 1990).

Reason, J. (2010). La gestión de los grandes riesgos. Principios humanos y organizativos de la seguridad. Editorial Modus Laborandi. Madrid. (Obra originalmente publicada em 1997). 
Reason, J. (2011). La contribución humana, Actos peligrosos y acciones ejemplares. Editorial Modus Laborandi. Madrid. (Obra originalmente publicada em 2008).

\section{NOTAS}

1. O denominado sistema HFACS (Human Factors Analysis and Classification System), ferramenta concebida para categorizar erros latentes e ativos, como explicação causal - linear - dos acidentes no setor da aviação, é um bom exemplo deste fenómeno.

2. Desde 2009, existe uma tradução espanhola da referida obra (ver nas referências bibliográficas).

3. Desde 2010, existe uma tradução espanhola da referida obra (ver nas referências bibliográficas).

4. Desde 2011, existe uma tradução espanhola da referida obra (ver nas referências bibliográficas).

5. Utilizam-se ambas as denominações, dado ter havido controvérsia entre os autores acerca da denominação mais adequada.

\section{ÍNDICE}

Temas: o Dicionário

\section{AUTOR}

\section{DIEGO TURJANSKI}

Institut pour une Culture de Sécurité industrielle, 6 allée Emile Monso, ZAC du Palays, BP 34038, 31029 Toulouse cedex 4, França

diego.turjanski@icsi-eu.org 